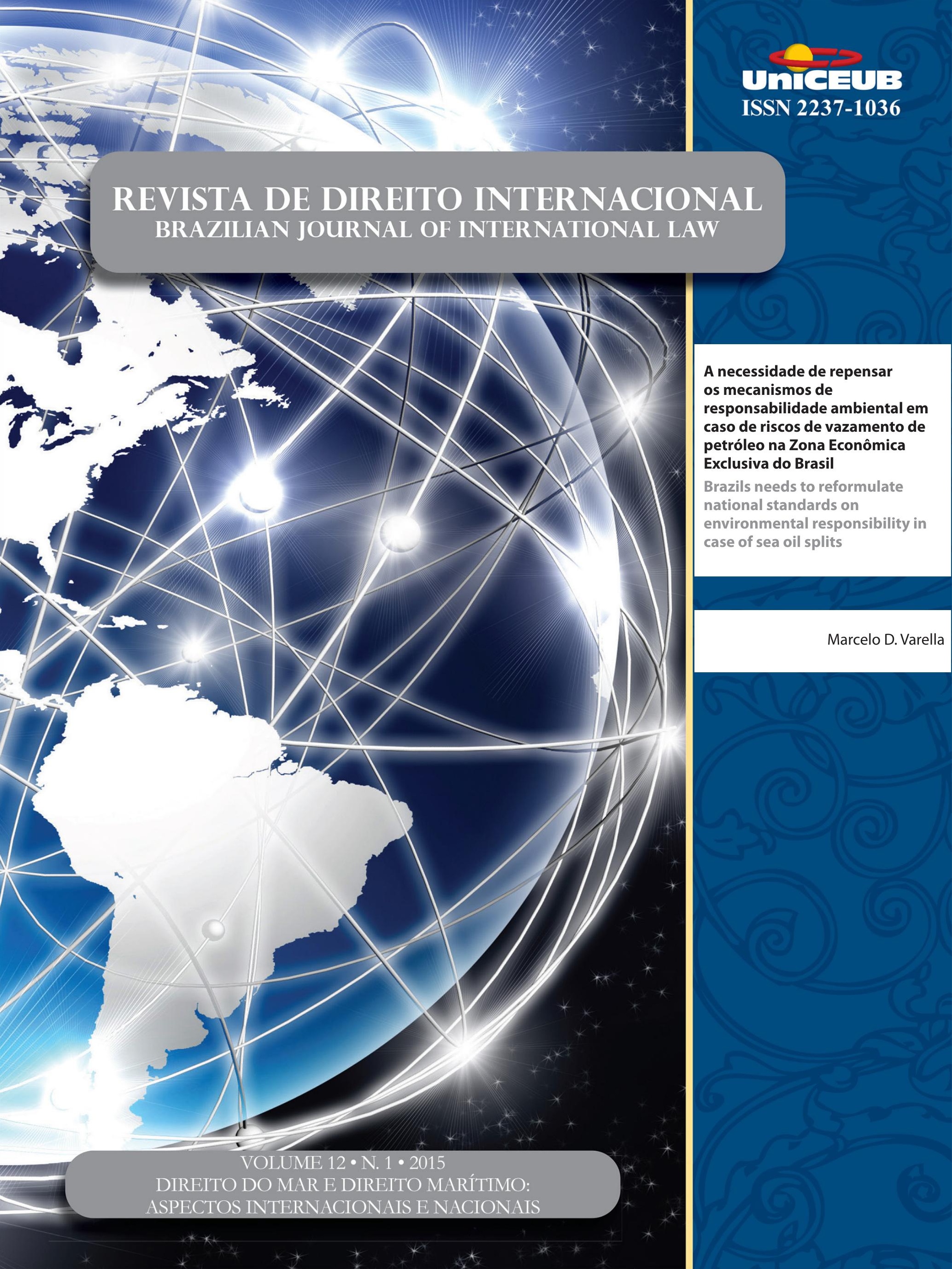




\section{Sumário}

\section{Crônicas}

CRôNICAS DA ATUALIDADE do DiREITO INTERNACIONAL ........................................................ 2

Nitish Monebhurrun (org.)

Towards a european regulation of the importation of conflict minerals?..... 2

Nitish Monebhurrun

Keeping up with the terrorists: the EU's proposed Passenger Name Records (PNR) Directive \& european security

Eshan Dauhoo

A histórica reaproximação de Cuba e EUA

Erika Braga

A contextualização da atual reivindicação da Grécia para receber indenizações por atos da Alemanha durante a Segunda Guerra Mundial . .10

Natália da Silva Gonçalves

José Eduardo Paiva Miranda de Siqueira

Crônicas da jurisprudência do Direito Internacional (CIJ/ITLOS): Decisões da Corte Internacional de Justiça e do Tribunal Internacional Sobre o Direito do Mar .14

Nitish Monebhurrun (Org.)

Corte Internacional de Justiça

Estudo da decisão da Corte Internacional de Justiça no caso Croácia v. Servia (03/02/2015) .14

Liziane Paixão Silva Oliveira e Maria Edelvacy Marinho

Questões relacionadas com a apreensão e detenção de certos documentos e dados: (Timor Leste c. Austrália) - O reconhecimento do retorno de uma relação amigável entre Timor-Leste e Austrália e a nova decisão da CIJ, 6 de maio de 2015 . 20

Gleisse Ribeiro Alves

Tribunal Internacional sobre Direito do Mar

Caso da delimitação da fronteira marítima entre o Gana e a Costa do Marfim no Oceano Atlântico: medidas cautelares $(25 / 04 / 2015)$

Nitish Monebhurrun

Comentário à Opinião Consultiva 21 do Tribunal Internacional para o Direito Do Mar [02/04/2015] (Responsabilidade do Estado de Bandeira pela pesca ilícita, não declarada ou não regulamentada) ...............25

Carina Costa de Oliveira 
CRÔNICAS DO DIREITO INTERNACIONAL DOS INVESTIMENTOS

Nitish Monebhurrun (Org.)

A inclusão da responsabilidade social das empresas nos novos Acordos de Cooperação e de Facilitação dos Investimentos do Brasil: uma revolução 33

Nitish Monebhurrun

\section{O Direito do Mar Perante as JuRisdições INTERnacionais}

CoAstal States' Rights IN THE MARITIME AREAS UNDER UNCLOS .40 Tullio Treves

TACKling illegal, unregulated And unReported Fishing: THE ITLOS Advisory OpINION on Flag State Responsibility for IUU fishing AND THE PRINCiple of DUE DiligenCE ...50 Victor Alencar Mayer Feitosa Ventura

REFLEXões PROVENIENTES do DisSENSO: UMA ANÁLISE CRÍtica A RESPEITO do CASO Austrália versus Japão Perante a Corte InTERnacional de JustiçA .......................................68 Luciana Ferna ndes Coelho

Os TRATADOS INTERNACIONAIS DE DIREITO DO MAR E SEUS EFEITOS SOBRE TERCEIROS ESTADOS ..... 86 Tiago V. Zanella

\section{InStRumentos JURÍdicos PARA A GeStÃo do MAR}

OS LIMITES DOS TERMOS BEM PÚBLICO MUNDIAL, PATRIMÔNIO COMUM DA HUMANIDADE E BENS COMUNS PARA DELIMITAR AS OBRIGAÇÕES DE PRESERVAÇÃO DOS RECURSOS MARINHOS 109 Carina Costa de Oliveira e Sandrine Maljean-Dubois

Os limites do PLANEJAMENTO DA OCUPAÇÃo SUSTENTÁVEL DA ZONA COSTEIRA BRASILEIRA ... 126 Carina Costa de Oliveira e Luciana Coelho

CORRENDO PARA O MAR NO ANTROPOCENO: A COMPLEXIDADE DA GOVERNANÇA DOS OCEANOS E A ESTRATÉGIA BRASILEIRA DE GESTÃO DOS RECURSOS MARINHOS 
A comissão de limites da Plataforma continental (CLPC) E Os DESAFios Na delineaÇÃo DAS PLATAFORMAS CONTINENTAIS ESTENDIDAS................................................... 170

Alexandre Pereira da Silva

\section{A PROTEÇÃo DO MEIO AMBIENTE MARINHO}

O gRANDE JOGo do ÁrTiCo: REFLEXões COM BASE NA PERSPECTIVA DE EXPLORAÇão ECONÔMICA

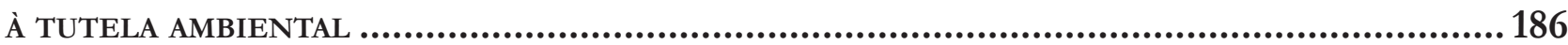

Fernando Rei e Valeria Cristina Farias

Instrumentos Públicos e Privados para a reparação do dano ambiental causado por DERRAMAMENTO DE ÓLEO NO MAR SEM ORIGEM DEFINIDA: AS MANCHAS ÓRFÃS

Renata Brockelt Giacomitti e Katya R. Isaguirre-Torres

O DIREITO INTERNACIONAL PRIVADO E A RESPONSABILIDADE CIVIL EXTRACONTRATUAL POR DANOS AMBIENTAIS CAUSADOS POR TRANSPORTES MARÍTIMOS À LUZ DO DIREITO BRASILEIRO ....... 217 Inez Lopes

A NECESSIDADE DE REPENSAR OS MECANISMOS DE RESPONSABILIDADE AMBIENTAL EM CASO DE riscos de VAZamento de PETRóleo Na Zona Econômica Exclusiva do BrasiL

Marcelo D. Varella

\section{Problemáticas do Direito Marítimo}

A FisCALIZAÇão SANitÁRIA DAS EMBARCAÇÕES EM ÁGUAS JURISDICIONAIS BRASILEIRAS: NOTAS aCERCA da (IN)efetividade da Súmula 50 da AGU

Joedson de Souza Delgado e Ana Paula Henriques da Silva

A IMO E A REPRESSÃo AO ROUBO ARMADO CONTRA NAVIOS: DA RETÓRICA INTERNACIONAL À COOPERAÇÃO REGIONAL

André Panno Beirão e Charles Pacheco Piñon

\section{O Direito do Mar diante da Pirataria}

O DIREITO INTERNACIONAL EM FACE DA PIRATARIA EM ALTO-MAR: UMA PERSPECTIVA CRÍTICA.289 Maiquel Ângelo Dezordi Wermuth e Rafaela Correa 
Pirataria marítima: A EXPERIÊnCIA Somália

Eduardo Augusto S. da C. Schneider

\section{Temas Gerais}

DRAWING THE LINE: ADDRESSING ALLEGATIONS OF UNCLEAN HANDS IN INVESTMENT ARBITRATION*

Mariano de Alba

Para Que Serve a história do Direito internacional?

George Rodrigo Bandeira Galindo

As interferências entre a Política Externa e de Segurança Comum Europeia (Pesc) e O DiREITO DAS NaÇões UNIDAS

Leonardo de Camargo Subtil

Introdução Às regras de aplicaÇão da Convenção da ONU Sobre Contratos de ComPRA E VENDA INTERNACIONAL DE MERCADORIAS E O DIREITO INTERNACIONAL PRIVADO BRASI-

LEIRO 380

Paul Hugo Weberbauer e Eugênia Cristina Nilsen Ribeiro Barza

A REgulaÇÃo das EMPRESAS TRANSNACIONAIS ENTRE AS ORDENS JURÍDICAS ESTATAIS E NÃO ESTATAIS.

Mateus de Oliveira Fornasier e Luciano Vaz Ferreira

OUtLAWING HATE SPEECH IN DEMOCRATIC STATES: THE CASE AGAINST THE INHERENT LimitAtions doctrine concerning Article 10 (1) of the European Convention on Human

Rights 416

Stefan Kirchner 


\title{
A necessidade de repensar os mecanismos de responsabilidade ambiental em caso de riscos de vazamento de petróleo na Zona Econômica Exclusiva do Brasil*
}

\author{
Brazils needs to reformulate national \\ standards on environmental responsibility in \\ case of sea oil splits
}

Marcelo D. Varella**

\section{Resumo}

O Brasil tornou-se um dos mais importantes produtores de petróleo na Zona Econômica Exclusiva. No entanto, parte relevante da exploração ocorre na Zona Econômica Exclusiva, além da jurisdição civil e penal brasileira. Os órgãos de controle têm dificuldades em aplicar multas e penas, como bem demonstra os casos dos vazamentos recentes. Além disso, o valor das multas é incompatível com a natureza das atividades econômicas. Assim, é preciso rever a legislação e os mecanismos extrajurídicos de efetividade do direito ambiental, para a proteção do meio ambiente marinho.

Palavras-chaves: Produção de petróleo no pré-sal; responsabilidade ambiental; zona econômica exclusiva.

\section{Abstract}

Brazil has become one of the most important producers of oil at sea. However, the relevant part of the production occurs in the Exclusive Economic Zone, outside Brazilian civil and criminal jurisdiction. Government hasn't competence to control, impose penalties as shows recent cases of oil leaks. In addition, the amount of dammages is incompatible with the nature of these economic activities. Thus, it is necessary to review the legal framework and find extra-legal mechanisms of effectiveness of environmental law for the protection of the marine environment.

Keywords: Oil production on pre-salt area; environmental responsibility; economic exclusive zone.

\section{INTRODUÇÃo}

O arcabouço jurídico brasileiro para exploração de petróleo é frágil no tocante à responsabilidade das empresas envolvidas. A falta de jurisdição na Zona Econômica Exclusiva, aliada à baixa capacidade de controle das

\footnotetext{
** Professor do Centro Universitário de Brasília. Doutor em Direito pela Universidade de Paris. Livre-Docente pela USP. Pesquisador do CNPq. Email: marcelodvarella@gmail.com
} 
agências governamentais leva a um cenário importante de risco. É preciso repensar o quadro jurídico em vigor, para ampliar as possibilidades de prevenção e reparação de danos.

O Brasil agora está tentando consolidar sua ascensão como a sexta maior economia do mundo, ultrapassando o Reino Unido. Parte do crescimento econômico brasileiro é atrelado a expansão da exploração petrolífera. A crise na Petrobrás decorrente da operação Lava Jato, da Política Federal, retardou o processo, mas a produção da Petrobrás off shore apenas aumenta a cada ano. O investimento em tecnologia, em especial nas tecnologias de produção de petróleo nacionais, criou economia dinâmica e aumentou o número de multinacionais interessadas na exploração de petróleo no Brasil. Novas descobertas transformaram o Brasil de importador em exportador de petróleo.

Um compromisso correspondente a regulamentar a exploração de petróleo e proteger o ambiente, no entanto, não ocorreu no Brasil. O quadro normativo permanece frágil e não está estruturado o suficiente para responder aos riscos apresentados pela exploração de petróleo na plataforma continental.

Recentemente, em 2011, o Brasil experimentou um grande problema de poluição ambiental com a produção de petróleo em águas profundas na plataforma continental. Um acidente em uma plataforma de perfuração da Chevron lançou milhares de barris de petróleo no mar. $\mathrm{O}$ acidente, embora de dimensões muito menores do que outros acidentes no exterior, destaca fragilidades no quadro jurídico e institucional brasileiro, bem como na capacidade de resposta em casos de emergência, pontos fracos que devem ser corrigidos no futuro.

Nesse artigo, descrevemos os recentes avanços na exploração de petróleo offshore, necessários para compreender a necessidade de proteção ambiental. Em seguida, avaliamos a efetividade das regras de proteção ambiental aplicáveis ao petróleo produzido na Zona Econômica Exclusiva, portanto, fora do território brasileiro, em especial na camada pré-sal.

Concluímos o ensaio, discutindo a necessidade de um sistema de responsabilidade compartilhada, mas diferenciada, entre empresas privadas e instituições públicas consiste no melhor mecanismo para assegurar melhor proteção do ambiente.

\section{Exploração de petróleo no Brasil}

O Brasil iniciou produção nacional de petróleo na década de 1930 com várias empresas estrangeiras. Em 1953, o governo federal nacionalizou a produção de petróleo, excluindo todas as empresas estrangeiras e criando estatal Petróleo do Brasil SA (Petrobras). Petrobras tornou-se empresa de capital aberto, controlada pelo governo federal. ${ }^{1}$ Em 1989, o governo do presidente Fernando Henrique Cardoso reabriu exploração petrolífera nacional a empresas estrangeiras em $1993 .^{2}$

Em 2003, após o aumento substancial de capital, a Petrobras e empresas estrangeiras descobriram novas reservas de petróleo em várias partes do país, predominantemente na plataforma continental. Essas descobertas resultaram na expansão rápida da produção nacional. Em 2006, a produção de petróleo no Brasil superou a demanda doméstica pela primeira vez, e as exportações, aumentaram significativamente. ${ }^{3}$ O Brasil exporta petróleo bruto e alguns derivados, mas continua a importar gasolina e outros produtos.

Em 2007, a paisagem nacional da exploração do petróleo mudou profundamente. A Petrobras descobriu enormes reservas de petróleo em águas ultraprofundas ao largo da sua costa, na chamada camada do pré-sal. ${ }^{4}$ Até então, nenhum país tinha produzido como base em óleo tais profundidades, 5000-8000 metros abaixo do oceano e a 180 milhas da costa. A camada de petróleo do pré-sal se estende cerca de 500 milhas com base em

1 A Petrobras é uma das mais antigas empresas estatais nacionais de petróleo em todo o mundo. Desenvolve atividade em toda a cadeia petrolífera. Em agosto de 2000, a Petrobras emitiu US \$4,3 bilhões em um IPO no Brasil e NYSE, não só para os investidores institucionais, mas também para as pessoas. Mais de 400.000 brasileiros e muitos investidores compraram ações da empresa. GOLDSTEIN, Andrea. The emergence of multilatinas: the Petrobras experience. Universia Business Review, Madrid, n. 25, p. 98-111, 2010.

2 LUCCHESI, Celso Fernando. Petróleo. Estudos Avançados, São Paulo, v. 12, n. 33, p. 17-40, maio/ago. 1998. p. 3.

3 SEABRA, Alessandra Aloise de et al. A Provincia promissora fazer pré-sal. Revista Direito GV, São Paulo, v. 7, n. 1, p. 57-74, jan./jun. 2011.

4 Cada país tem costal, de acordo com a Convenção das Nações Unidas sobre o Direito do Mar, uma Zona Económica Exclusiva (ZEE). O ZEE normalmente inclui 200 milhas náuticas (cerca de 370 quilômetros) a partir da linha de base costeira do país. O território nacional, onde os Estados têm jurisdição legal, vai até 12 milhas marítimas, mas o monopólio sobre a exploração económica do mar e de fundo marinho vai muito além, a 200 milhas náuticas. Os países podem solicitar uma extensão da ZEE em algumas circunstâncias, de acordo com a Comissão das Nações Unidas sobre os Limites da Plataforma Continental regra (CLCS). 
estado de Santa Catarina até o estado do Espírito Santo, dentro da Zona Económica Exclusiva (veja o polígono no mapa abaixo). Novos achados foram descobertos recentemente em toda a área. Em meados de 2012, foram confirmados mais de 15 bilhões de barris. Se as estimativas de 50 a 80 bilhões de barris de petróleo e gás forem confirmadas, o Brasil será o sexto maior possuidor de reservas de petróleo e gás, depois da Arábia Saudita, Irã, Iraque, Kuwait, e os EAU. ${ }^{6}$

Figura 1 - Mapa da área do pré-sal

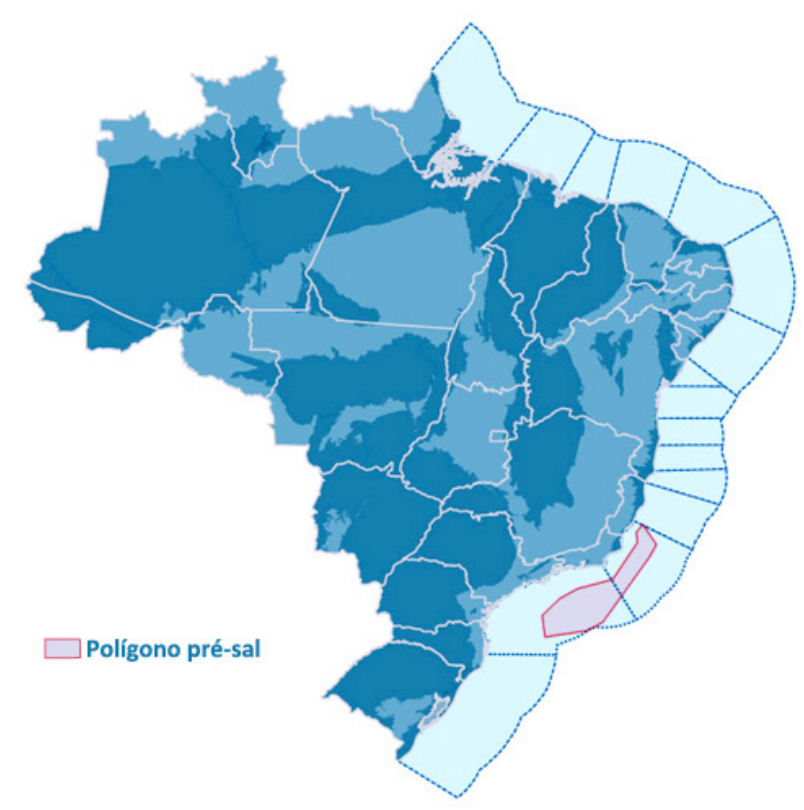

Fonte: Agência Nacional de Petróleo (ANP).

Vários especialistas argumentavam que a extração de petróleo da área do pré-sal seria impossível, já que os custos seriam proibitivos e a tecnologia ainda não existia. Para viabilizar a produção, a Petrobrás precisou obter mais de US $\$ 220$ bilhões por meio de venda de ações na bolsa de valores.

O Governo brasileiro considerou que seria também necessário rever o quadro jurídico sobre exploração petrolífera e proteção ambiental. ${ }^{5}$ Até as descobertas do pré-sal, o Brasil tinha um conjunto de normas favorável ao investimento estrangeiro na exploração de petróleo, mas pouco sobre segurança e proteção ao meio ambiente. O país havia realizado concessões de exploração em determinados blocos a empresas estrangeiras para a produção offshore. Quando a Petrobras abriu-se ao

5 PERGUNTAS e respostas: pré-sal. Set. 2009. Disponível em: $<$ http://veja.abril.com.br/idade/exclusivo/perguntas_respostas/ pre-sal/>. Acesso em: 08 out. 2013. investimento estrangeiro, cerca de $60 \%$ do seu capital pertencia a fundos de investimento estrangeiros.

O governo brasileiro decidiu, em 2010, recapitalizar a empresa em processo aberto e expandiu o seu papel na administração da empresa. Em troca de número de ações, o governo nacional concedeu Petrobras o direito de extrair 5 bilhões de barris de petróleo, o que aumentou o valor de mercado da empresa. Foi a maior operação de capital de história das bolsas de valores em todo o mundo, somando US\$ 64,5 bilhões. ${ }^{6}$ Quaisquer investidores poderiam comprar ações da empresa durante esse processo. Em virtude do aporte de recursos, a participação do governo brasileiro aumentou para $47,8 \%$ da capitalização total da empresa, dando o controle do governo nas decisões da empresa e na divisão dos lucros.

O Congresso brasileiro modificou a legislação sobre exploração de petróleo. A Petrobras deveria participar diretamente de pelo menos $30 \%$ de qualquer projeto de exploração. ${ }^{7} \mathrm{O}$ novo quadro jurídico aumentou os royalties do governo sobre novos contratos de petróleo. Uma vez que a participação na empresa era maior e a cobrança de royalties também havia aumentado, o Estado receberia uma participação mais importante da exploração de petróleo no país. Criou-se então um fundo nacional alimentado pelos royalties e outros lucros do petróleo para promover novos investimentos, principalmente em educação e saúde, mas também na proteção do ambiente, ciência e tecnologia em todo o país.

O quadro jurídico, os poços localizados fora da área do pré-sal permaneceram inalterados. Muitas empresas estrangeiras já haviam iniciado a produção no Brasil, como Anadarko, Devon, a Exxon-Mobil, BG Group, Petrogal, Repsol, Shell, Devon, EnCana, SK e UK Gas Company e se decidiu honrar os compromissos firmados. $^{8}$

A produção offshore representa hoje $94,3 \%$ da produção nacional de petróleo do Brasil e 75,8\% da produção

6 ELLSWORTH, Brian. Petrobras to sell $\$ 65$ billion stock in record offer. Disponível em: <http://www.reuters.com/article/2010/09/03/ us-petrobras-idUSTRE6821FX20100903>. Acesso em: 08 out. 2013.

7 BRASIL. Lei no 12.351, de 22 de dezembro de 2010. Disponível em: <http://www.planalto.gov.br/ccivil_03/_Ato2007-2010/2010/ Lei/L12351.htm>. Acesso em: 08 out. 2013. Art. 10, I, c.

8 AGÊNCIA NACIONAL DO PETRÓLEO, GÁS NATURAL E BIOCOMBUSTIVEIS. Página principal. Disponível em: $<$ hwww. anp.gov.br>. Acesso em: 08 out. 2013. 
nacional de gás. Empresas estrangeiras, como Peregrino, a Statoil, Ostra, e Shell controlar alguns dos locais de perfuração mais produtivos, fora da pré-sal. No entanto, a produção das reservas de pré-sal vem aumentando a cada ano e já ultrapassa os 700 mil barris por dia. ${ }^{9}$ Os investimentos maciços nas reservas do pré-sal mostram o quão importante a produção de petróleo em águas profundas vai se tornar nos próximos anos. Ele também prenuncia muitos desafios.

Em suma, as empresas estão investindo recursos financeiros muito elevados, e eles estão usando uma tecnologia nunca antes utilizada no mundo, em uma área fora da jurisdição penal do Estado, com grande potencial de impacto ambiental. Ao mesmo tempo, o óleo é considerado indispensável para o desenvolvimento do país. Esse cenário formidável sublinha a importância de um quadro jurídico correto para evitar desastres graves.

\section{O MODELO BRASILEIRO PARA PREVENIR DANOS AMBIENTAIS COM A EXPLORAÇÃO MARÍTIMA DE PETRÓLEO}

O principal instrumento legal para a exploração de petróleo no Brasil consiste na Lei n ${ }^{\circ} 9.966$ de 28 de abril de 2000, que tem suas origens nas Convenções Internacionais para a Prevenção da Poluição por Navios de 1973 e 1978; na Convenção Internacional sobre a Responsabilidade Civil por Danos da Poluição por Óleo, de 1969, alterada em 1992; e na Convenção Internacional sobre Preparo, Resposta e Cooperação em caso de Poluição por Óleo, de 1995. Essas normas delineiam quatro níveis de risco para os ecossistemas marinhos: alta, média, moderada e baixa. ${ }^{10}$

Cada plataforma deve ter o equipamento necessário para lidar com acidentes de petróleo. As especificações de cada equipamento dependem de estudo técnico, com base nas dimensões e localização da plataforma, os métodos de controle operacional, as qualificações e o número de pessoas envolvidas, bem como o cronograma

9 INFORME CONJUNTURA E INFORMAÇÃO. Rio de Janeiro: ANP, 200?. Disponível em: <www.anp.gov.br>. Acesso em: 8 maio 2015.

10 Os limites da responsabilidade civil extracontratual podem ser vistos neste número em LOPES, I. O direito internacional privado e a responsabilidade civil extracontratual por danos ambientais causados por transportes marítimos à luz do direito brasileiro in Revista de Direito Internacional, v. 12, n.1, 2015. para a implementação do projeto de exploração. ${ }^{11}$ As normas definem regras para evitar a poluição, exigências de relatórios periódicos, obrigações para as empresas públicas e privadas de instituir planos preventivos para evitar a poluição marinha.

A análise dos aspectos de engenharia de exploração de petróleo e da segurança das operações deve ser aprovado pela Agência Nacional do Petróleo, Gás e Biocombustíveis (ANP) e realizado antes da implementação do projeto. Alguns aspectos também são controlados pela Marinha, que deve atestar a conformidade das plataformas em relação à segurança da navegação, à capacidade de armazenamento, e à prevenção de acidentes.

A principal diferença operacional entre os sistemas brasileiro e americano refere-se ao fato de que, nos Estados Unidos, técnicos especializados da própria empresa devem controlar plataformas de perfuração in loco, o tempo todo. Há menos controle do Estado, mas sanções mais severas em caso de problemas. No Brasil, uma equipe de funcionários públicos visita e fiscaliza a plataforma durante três ou quatro dias e controlam os principais riscos operacionais. Há maior controle do Estado e menor responsabilização em caso de danos. De acordo com a ANP, há menos chances de acidentes. $^{12}$

O sistema brasileiro baseia-se num modelo de comando e controle. Ele impõe sanções, e funcionários do governo controlam cada plataforma pessoalmente. As normas exigem que cada plataforma tenha plano adequado às suas características particulares. Os fiscais deve controlar cada detalhe. O Instituto Brasileiro de Proteção Ambiental (IBAMA) e da Agência Nacional de Petróleo, Gás Natural e Biocombustíveis devem fornecer pessoal aos sites para supervisionar os detalhes da extração e produção.

Duas semelhanças preocupantes entre as autoridades regulatórias brasileiras e americanas se destacam. Em primeiro lugar, a mesma agência responsável pela promoção da produção de petróleo historicamente tem sido também responsável por controlar e fiscalizar as operações de segurança ambiental. Como nos Esta-

11 Art. 5. da Lei 9.966, de 2000. BRASIL. Lei $n^{\circ}$ 9.966, de 28 de abril de 2000. Disponível em: <http://www.planalto.gov.br/ccivil_03/leis/L9966.htm>. Acesso em: 08 out. 2013.

12 Entrevista com Rafael Neves Moura, chefe da Operacional e Segurança Ambiental da Agência Nacional de Petróleo e Gás, em 2013. 
dos Unidos, a mesma agência responsável por aumentar a produção de petróleo é a responsável pela segurança das plataformas. Esse acúmulo de funções constitui um erro cometido nos Estados Unidos, muito criticado nas decisões judiciais decorrentes do acidente da BP e que poderia ser evitado no Brasil. Além disso, há claramente falta de pessoal para realizar a fiscalização, o que, aliás, se repete em quase todos os departamentos responsáveis por qualquer fiscalização no país.

A ANP prevê a publicação de plano de contingência nacional a ser negociado e aprovado pela ANP em cooperação com órgãos ambientais ${ }^{13}$. As discussões continuam, particularmente após o acidente da BP no Golfo do México nos Estados Unidos e do acidente da Chevron no Brasil, mas nenhuma lei ou princípios ainda não foram acordados. ${ }^{14}$

Além disso, o Brasil não tem normas para proteger áreas sensíveis, como os ecossistemas marinhos de alta biodiversidade. $\mathrm{O}$ artigo 28 da lei sobre a exploração de petróleo exige que o governo delinear áreas protegidas, onde a exploração de petróleo, transporte e poluição associada são proibidos. No entanto, o governo brasileiro não realizou essas delimitações geográficas.

\section{Problemas institucionais: Um estudo de caso da Chevron}

O acidente da Chevron ocorreu a 40 milhas da costa do Rio de Janeiro, fora da área do pré-sal, mas também além do mar territorial brasileiro. ${ }^{15} \mathrm{O}$ poço estava sendo perfurado a 1200 metros de profundidade, teoricamente mais controlável do que qualquer poço na camada mais profunda pré-sal, onde as pressões e condições são muito mais difíceis de se lidar. Em 8 de novembro de 2011, a Petrobrás identificou a mancha de óleo na superfície e, por meio de um veículo operado remotamente, localizou sete rachaduras no fundo do mar. As maiores

13 Para o Plano Nacional de Contigência, veja o artigo de GIACOMITTI, R. B e ISAGUIRRE-TORRES, K. R. Instrumentos públicos e privados para a reparação do dano ambiental causado por derramamento de óleo no mar sem origem definida: as manchas órfãs in Revista de Direito Internacional, v. 12, n.1, 2015.

14 Entrevista com o Gerente de Segurança Operacional da Agência Nacional de Petróleo e Gás no Brasil, em Dezembro de 2012.

15 A Chevron detém uma concessão nesta plataforma de petróleo com a Petrobras. (Número do contrato 48.000,003896/97-20). rachaduras tinham cerca 1000 pés de comprimento. ${ }^{16} \mathrm{O}$ total de petróleo derramado foi de cerca de 4600 barris.

O Instituto Nacional de Proteção Ambiental e a Agência Nacional de Petróleo ordenaram que Chevron iniciasse imediatamente a execução do seu plano de contingência. O plano havia sido formulado pela Chevron e foi previamente aprovado pelos órgãos ambientais nacionais do Brasil como pré-requisito para obtenção da concessão e início da produção de petróleo. ${ }^{17}$

Embora a Chevron tivesse identificado no seu plano de contingência o equipamento que usaria para responder a um evento como este, o equipamento não foi posicionado no Brasil, mas sim nos Estados Unidos! Consequentemente, a Chevron não foi capaz de controlar a descarga, que foi estimada pelo IBAMA em três mil barris. ${ }^{18} \mathrm{Em}$ março de 2012, a Chevron identificou a segunda vazamento de óleo, menor, a apenas 2 milhas do primeiro.

Uma vez que Chevron não tinha o equipamento necessário, a Petrobrás iniciou seu plano de contingência. Contudo, o vazamento se tornou maior do que deveria. Ao final do processo, a Petrobras gastou USD 748.423 para lidar com o problema e a Chevron gastou outros USD 173.934.000. ${ }^{19}$

Durante o processo judicial, a Chevron argumentou que uma única empresa normalmente não tem equipamento disponível para o seu plano de contingência em cada plataforma. Para reduzir custos, é comum compartilhar essas instalações com outras companhias petrolíferas na mesma área. As autoridades consideraram que o investimento na prevenção era demasiado baixo para evitar riscos consideráveis. Em 2011, a Petrobras, por exemplo, investiu apenas $0,022 \%$ do seu orçamento na proteção do ambiente e apenas $0.092 \mathrm{em} \mathrm{2012.{ } ^ { 2 0 }}$

16 Relatório da Petrobras, ligado ao Processo n. 02000.002345 / 2011-4.

17 Relatório da Petrobras, ligado ao Processo n. 02000.002345 / 2011-4.

18 Relatório da Petrobras, ligado ao Processo n. 02000.002345 / 2011-4.

19 BRASIL. Procuradoria da República no Estado do Rio de Janeiro $20^{\circ}$ Ofício. Meio Ambiente e patrimônio cultural. Termo de compromisso de ajustamento de conduta que entre si celebram de um lado o Ministério Público Federal e de outro Cheuron Brasil Upstream Frade LTDA., Cheuron América Latina Marketing LLC e Transocean Brasil Ltda. com a interveniência da Agência Nacional do Petróleo, Gás Natural e Biocombustiveis - ANP e do Instituto Brasileiro do Meio Ambiente e dos Recursos Naturais Renováveis- Ibama. Rio de Janeiro, 13 de Setembro de 2013. Disponível em: <http://s.conjur.com.br/dl/tac-chevron-mp-ibama. pdf>. Acesso em: 15 jul. 2015.

20 BRASIL. Tribunal de Contas da União. Relatório de Audito- 
O IBAMA aplicou à Chevron multa de US\$ 22 milhões, a pena máxima existente. A ANP aplicou segunda multa de US\$12 milhões. A Chevron recorreu da primeira multa no Judiciário, que anulou a pena do IBAMA. Em seguida, a Chevron concordou em pagar a multa da ANP. ${ }^{21}$ As duas principais acusações contra a empresa eram de que esta não possuía o equipamento exigido pelo plano de contingência e que tinha adulterado as imagens do fundo do mar rachado obtidas pelo veículo operacional remoto, para minimizar o problema.

Poucos meses depois, antes da investigação chegar ao fim, um segundo vazamento de óleo ocorreu no mesmo local de perfuração. Como no primeiro exemplo, a pressão utilizada na extração foi maior do que o fundo do mar suportava e fissuras se desenvolveram, permitindo o vazamento de óleo.

De acordo com um relatório da Agência Nacional de Meio Ambiente (IBAMA), ${ }^{22}$ o acidente foi o resultado de vários erros cometidos pela Chevron: falha no cálculo das condições reais de exploração, medições imprecisas de riscos potenciais, fracasso do plano de contingência, omissão de informações, falta de limpeza do oceano depois do vazamento de óleo, falta de êxito no controle do processo de exploração. O plano de contingência foi formulado com base em um projeto de

ria. TC-037.197/2011-8. Plenário. Órgão Entidade: Petróleo Brasileiro S.A.(Petrobras). Interessado: Tribunal de Contas da União. Relator: Relator: Min. José Jorge de Vasconcelos Lima. Brasília, 22 de outubro de 2014. Disponível em: <portal2.tcu.gov.br/portal/.../037.197\%20(Campo\%20de\%20Frade).rtf>. Acesso em: 15 jul. 2015. p. 13; 18.

21 Chevron pagou $\mathrm{R} \$ 42.8566 .010$ porque antecipou o pagamento. BRASIL. Procuradoria da República no Estado do Rio de Janeiro $20^{\circ}$ Ofício. Meio Ambiente e patrimônio cultural.. Termo de compromisso de ajustamento de conduta que entre si celebram de um lado o Ministério Público Federal e de outro Chevron Brasil Upstream Frade LTDA., Chevron América Latina Marketing LLC e Transocean Brasil Ltda. com a interveniência da Agência Nacional do Petróleo, Gás Natural e Biocombustiveis - ANP e do Instituto Brasileiro do Meio Ambiente e dos Recursos Naturais Renováveis- Ibama. Rio de Janeiro, 13 de Setembro de 2013. Disponível em: <http://s.conjur.com.br/dl/tac-chevron-mp-ibama. pdf>. Acesso em: 15 jul. 2015. p. 11.

22 INSTITUTO NACIONAL DE MEIO AMBIENTE. Nota Informativa CPEG/DILIC/IBAMA n ${ }^{\circ}$ 01/12 de 05 de Janeiro de 2012. Disponível em: <http://www.mma.gov.br/port/conama/ processos/DC218947/ParecerIBAMA.pdf.>. Acesso em: 09 maio 2015. Ver BRASIL. Tribunal de Contas da União. Relatório de Auditoria. TC-037.197/2011-8. Plenário. Órgão Entidade: Petróleo Brasileiro S.A.(Petrobras). Interessado: Tribunal de Contas da União. Relator: Relator: Min. José Jorge de Vasconcelos Lima. Brasília, 22 de outubro de 2014. Disponível em: <portal2.tcu.gov.br/por$\mathrm{tal} / . . . / 037.197 \% 20$ (Campo\%20de $\% 20$ Frade).rtf $>$. Acesso em: 15 jul. 2015. p. 11 extração de menor escala muito e não era realista no local explorado real. Parece que o plano foi preparado para outras áreas e reutilizados pela Chevron.

Uma segunda investigação, envolvendo a Petrobras e a Chevron, realizada pela ANP, concluiu que (i) várias unidades em operação não tinham passado por auditorias por parte do Sistema de Gestão de Segurança Operacional (SGSO); (ii) nenhuma inspeção preliminar das plataformas ou instrumentos tinha sido realizada para confirmar a existência e a condição de elementos críticos de segurança da central no momento da aprovação da Documentação de Segurança Operacional (DSO); e (iii) as investigações de incidentes não respeitavam aos regulamentos necessários, e os resultados não foram amplamente divulgados, conforme exigido. ${ }^{23}$

A Chevron suspendeu todas as suas atividades no Brasil, e seus executivos deixaram o país até meados de 2012, quando a empresa pediu permissão para reiniciar as atividades de extração no mesmo local de produção. Em abril de 2013, a produção foi reiniciada e intensificada a partir de março de 2014.

O Ministério Público Federal iniciou dois processos contra a Chevron e as duas empresas responsáveis pelas operações da plataforma e pelo plano de contingência - Transocean e Halliburton. A primeira ação foi por danos civis. A segunda buscava a aplicação de sanções penais, solicitando US $\$ 10$ bilhões em danos e a prisão dos dezessete funcionários da Chevron responsáveis pelas falhas que levam ao desastre ${ }^{24}$. O Tribunal de Justiça do Rio Criminal rejeitou finalmente a ação penal em 20 de fevereiro de 2013, porque o acidente ocorrera fora da jurisdição penal brasileira. Nos casos do pré-sal, essa seria a regra.

A Chevron defendeu-se na ação civil com os mesmos argumentos, alegando que o acidente tinha ocorrido fora do território brasileiro. Conforme determinado pela Convenção das Nações Unidas sobre o Direito do

23 OPERAÇÃO no Campo Frade: primeira produção teve início em 2009. Disponível em: <https://www.chevron.com.br/negocios/exploracao-producao-petroleo/campo-frade.aspx > Acesso em: 09 maio 2015.

24 Solicitava-se o valor da condenação em 20 bilhões de reais, aproximadamente US \$ 10 bilhões, em 2013. BRASIL. Ministério Público Federal. Procuradoria da República no Município de Campos dos Goytacazes (RJ). Ação Civil Pública com Pedidos de Liminar. Campos dos Goytacazes, 02 de abril de 2012. Disponível em: $<$ http://s.conjur.com.br/dl/acao-civil-publica-chevron-mpf.pdf $>$. Acesso em: 09 maio 2015. 
Mar (CNUDM), existem três áreas mais adentro, com diferentes status legais: o mar territorial, a zona contígua, e na zona econômica exclusiva. O mar territorial começa no litoral normal e se estende para fora $12 \mathrm{mi}$ lhas náuticas. A zona contígua se estende até 24 milhas náuticas. A zona econômica exclusiva, na qual ocorre a maior parte da produção brasileira de petróleo, se estende a 200 milhas náuticas da costa. Em situações em que a plataforma continental se estende mais de 200 milhas náuticas da costa, na zona econômica exclusiva, estende-se à mesma distância, até 350 milhas náuticas, embora apenas no fundo do mar. ${ }^{25}$

Dentro da zona econômica exclusiva, o Estado costeiro tem o direito soberano de explorar e extrair recursos naturais, vivos ou não. Ele também tem jurisdição para proteger e preservar os ambientes marinhos localizados naquele local ${ }^{26}$. No entanto, não há nenhuma competência penal sobre os fatos acontecidos na área pelo Brasil, exceto se a bandeira da nave for brasileira.

No caso Chevron, a Justiça Federal do Rio de Janeiro decidiu pela sua incompetência porque o acidente ocorreu fora do território brasileiro (na Zona Econômica). Este parece ser um dos principais desafios da exploração da camada pré-sal no Brasil. Uma vez que a zona se encontra fora da jurisdição nacional, o Brasil tem o monopólio da exploração, mas não tem jurisdição criminal e civil. O Ministério Público Federal recorreu dessa decisão. ${ }^{27}$

Em setembro de 2013, a Chevron assinou acordo com a Procuradoria da República, o IBAMA, e a ANP para pagar quase US $\$ 48$ milhões, recursos que seriam investidos em medidas preventivas e de precaução para melhorar a capacidade de acompanhamento do IBAMA para evitar novos derrames de hidrocarbonetos. ${ }^{28} \mathrm{~A}$ Chevron se comprometei a implementar o plano de emergência; manter duas instalações fluviais para evitar os derrames de petróleo e outros danos, integradas

25 Ver TREVES, Tullio. Coastal States' rights in the maritime areas under UNCLOS in Revista de Direito Internacional, v. 12, n.1, 2015.

26 Ver art. 56 de Convenção das Nações Unidas sobre o Direito do Mar. NAÇÕES UNIDAS. Convenção das Nações Unidas sobre o Direito do Mar e o acordo relativo à aplicação da parte XI da mesma convenção. Nova York, 10 de dezembro de 1982. Disponível em: < http://www. gddc.pt/siii/im.asp?id=396>. Acesso em: 16 jun. 2015.

27 Não houve nenhuma decisão no momento da elaboração deste capítulo. No entanto, a primeira decisão provavelmente seria confirmada.

$28 \mathrm{R} \$ 95.160 .000,00$. TAC - Chevron com um sistema de medição automática por raios infravermelhos para detectar óleo no mar, com imagens de ROV; instalar uma estação climática com sensores de vento; e implementar múltiplos sensores com saída para o mar disponível para o IBAMA. A ação penal continua, independentemente do acordo.

Em relação ao vazamento de petróleo Chevron, a Petrobras transferiu a responsabilidade para a prospecção de petróleo para Chevron. De acordo com a legislação brasileira, a Petrobras seria solidariamente responsável pelos danos, independentemente de culpa. No entanto, no Acordo de Operação Conjunta entre a Petrobras e a Chevron, afirma-se que, em caso de negligência grave ou dolo, a Chevron responde sozinha por qualquer indenização. Assim, a Chevron admitiu pagaria todas as multas sozinha. ${ }^{29}$

O Tribunal de Contas do Brasil realizou uma segunda auditoria em relação à responsabilidade da Petrobras para o acidente. Decidiu que a Petrobras deveria melhorar o seu plano de contingência. Sugeriu também que o IBAMA fosse mais exigente nas suas fiscalizações, inclusive fechando plataformas por falta de segurança, o que traria resultados mais efetivos, por gerar impactos econômicos mais significativos a empresas do que multas que representam um percentual ínfimo dos custos de operação.

\section{NeCESSIDADES DE REFORMAS}

Há vários obstáculos jurídicos e de políticas públicas para a proteção efetiva do meio ambiente, com a expansão do pré-sal, como os maiores riscos da produção, a falta de jurisdição, falta de pessoal suficiente e de instrumentos de responsabilidade compartilhada das empresas.

No tocante ao aumento dos riscos, a exploração de petróleo em águas ultraprofundas, em virtude das di-

29 Testemunho da diretora da ANP, ao Congresso . CAMBRIARD, Magda Maria de Regina apud. BRASIL. Congresso Nacional. Comissão Parlamentar Mista de Inquerito n. 302: destinada a investigar irregularidades envolvendo a empresa Petróleo Brasileiro S/A (PETROBRAS), ocorridas entre os anos de 2005 e 2014 e relacionadas à compra da Refinaria de Pasadena, no Texas (EUA); ao lançamento de plataformas inacabadas; ao pagamento de propina a funcionários da estatal; e ao superfaturamento na construção de refinarias - CPMIPETRO”: relatório final. Brasília, dez. 2014. Disponível em: <www.petrobras.com.br/lumis/portal/file/fileDownload>. Acesso em: 15 jul. 2015. 
ficuldades tecnológicas, a alta pressão e outros fatores ambientais, leva ao menor controle dos fatores de acidentes. Trata-se de nova tecnologia que exige esforços em proteção ambiental similares àqueles investidos na produção. ${ }^{30}$

A falta de jurisdição penal e cível do Estado brasileiro sobre essa região poderia ser compensada com a possibilidade de aplicação de sanções mais severas no âmbito administrativo, como a interdição da produção ou mesmo multas contratuais no processo de concessão de blocos de exploração. Por se tratarem de pessoas jurídicas, as penalidades econômicas podem ter efeitos mais importantes do que eventuais multas.

O valor das multas, por sua vez, deve ser proporcional aos valores oriundos da exploração de petróleo. Como vimos acima, as multas têm valor representativo, mas nesse universo de investimentos, acabam representando parcelas insignificantes do faturamento. Nesse caso, o ordenamento jurídico deve mudar sua lógica de sanção e não fixar valores monetários, mas percentuais de faturamento, como ocorre no direito da concorrência ou do combate à corrupção, por exemplo. Nesse caso, os contratos de concessão devem prever a possibilidade do valor da multa ser arbitrado em virtude do grau de culpa e da imputabilidade da empresa.

O órgão responsável pelas multas administrativas não pode ser o mesmo órgão responsável pelo estímulo à produção de petróleo. Como ficou bem evidente em outras experiências internacionais, a exemplo dos Estados Unidos, trata-se de sistema altamente ineficaz. Nos contratos de concessão, é importante destacar a possibilidade do IBAMA e não da ANP de fixar os valores adequados de multas, bem como a impossibilidade de continuar a exploração no país.

\section{REFERÊNCIAS}

AGÊNCIA NACIONAL DO PETRÓLEO, GÁS NATURAL E BIOCOMBUSTIVEIS. Página principal. Disponível em: < http://www.anp.gov.br>. Acesso em: 08 out. 2013.

30 BARROS-PLATIAU, A., BARROS et alii. Correndo para o mar antropoceno: a complexidade da governança dos oceanos e a estratégia brasileira dos recursos marinhos in Revista de Direito Internacional, v. 12, n. 1, 2015
BARROS-PLATIAU, A., BARROS et al. Correndo para o mar antropoceno: a complexidade da governança dos oceanos e a estratégia brasileira dos recursos marinhos in Revista de Direito Internacional, v. 12, n. 1, 2015

BRASIL. Congresso Nacional. Comissão Parlamentar Mista de Inquérito n. 302: destinada a investigar irregularidades envolvendo a empresa Petróleo Brasileiro S/A (PETROBRAS), ocorridas entre os anos de 2005 e 2014 e relacionadas à compra da Refinaria de Pasadena, no Texas (EUA); ao lançamento de plataformas inacabadas; ao pagamento de propina a funcionários da estatal; e ao superfaturamento na construção de refinarias - CPMIPETRO”: relatório final. Brasília, dez. 2014. Disponível em: <http://www.petrobras.com.br/lumis/portal/ file/fileDownload>. Acesso em: 15 jul. 2015.

BRASIL. Ministério Público Federal. Procuradoria da República no Município de Campos dos Goytacazes (RJ). Ação Civil Pública com Pedidos de Liminar. Campos dos Goytacazes, 02 de abril de 2012. Disponível em: $<$ http://s.conjur.com.br/dl/acao-civil-publica-chevron-mpf.pdf $>$. Acesso em: 09 maio 2015.

BRASIL. Procuradoria da República no Estado do Rio de Janeiro $20^{\circ}$ Ofício. Meio Ambiente e patrimônio cultural. Termo de compromisso de ajustamento de conduta que entre si celebram de um lado o Ministério Público Federal e de outro Cheuron Brasil Upstream Frade LTDA., Chevron América Latina Marketing LLC e Transocean Brasil Ltda. com a interveniência da Agência Nacional do Petróleo, Gás Natural e Biocombustiveis - ANP e do Instituto Brasileiro do Meio Ambiente e dos Recursos Naturais Renováveis - Ibama. Rio de Janeiro, 13 de Setembro de 2013. Disponível em: < http://s. conjur.com.br/dl/tac-chevron-mp-ibama.pdf $>$. Acesso em: 15 jul. 2015.

BRASIL. Tribunal de Contas da União. Relatório de Auditoria. TC-037.197/2011-8. Plenário. Órgão Entidade: Petróleo Brasileiro S.A.(Petrobras). Interessado: Tribunal de Contas da União. Relator: Relator: Min. José Jorge de Vasconcelos Lima. Brasília, 22 de outubro de 2014. Disponível em: <portal2.tcu.gov.br/ portal/.../037.197\%20(Campo\%20de $\% 20$ Frade).rtf $>$. Acesso em: 15 jul. 2015.

ELLSWORTH, Brian. Petrobras to sell $\$ 65$ billion stock in record offer. Disponível em: <http://www.reuters.com/article/2010/09/03/us-petrobras-idUSTRE6821FX20100903 >. Acesso em: 08 out. 2013 
GIACOMITTI, R. B e ISAGUIRRE-TORRES, K. R. Instrumentos públicos e privados para a reparação do dano ambiental causado por derramamento de óleo no mar sem origem definida: as manchas órfãs in Revista de Direito Internacional, v. 12, n.1, 2015.

GOLDSTEIN, Andrea. The emergence of multilatinas: the Petrobras experience. Universia Business Review, Madrid, n. 25, p. 98-111, 2010.

INFORME CONJUNTURA E INFORMAÇÃO. Rio de Janeiro: ANP, 200?. Disponível em: <www.anp.gov. br>. Acesso em: 8 maio 2015.

INSTITUTO NACIONAL DE MEIO AMBIENTE. Nota Informativa CPEG/DILIC/IBAMA n 01/12 de 05 de Janeiro de 2012. Disponível em: <http://www.mma. gov.br/port/conama/processos/DC218947/ParecerIBAMA.pdf.>. Acesso em: 09 maio 2015.

LOPES, I. O direito internacional privado e a responsabilidade civil extracontratual por danos ambientais causados por transportes marítimos à luz do direito brasileiro in Revista de Direito Internacional, v. 12, n.1, 2015. LUCCHESI, Celso Fernando. Petróleo. Estudos Avança- dos, São Paulo, v. 12, n. 33, p. 17-40, maio/ago. 1998.

NAÇÕES UNIDAS. Convenção das Nações Unidas sobre o Direito do Mar e o acordo relativo à aplicação da parte XI da mesma convenção. Nova York, 10 de dezembro de 1982. Disponível em: <http://www.gddc.pt/siii/ im.asp?id=396> . Acesso em: 16 jun. 2015.

OPERAÇÃO no Campo Frade: primeira produção teve início em 2009. Disponível em: <https:/ /www.chevron. com.br/negocios/exploracao-producao-petroleo/campo-frade.aspx> Acesso em: 09 maio 2015.

PERGUNTAS e respostas: pré-sal. Set. 2009. Disponível em: <http://veja.abril.com.br/idade/exclusivo/perguntas_respostas/pre-sal/>. Acesso em: 08 out. 2013.

SEABRA, Alessandra Aloise de et al. A Província promissora fazer pré-sal. Revista Direito GV, São Paulo, v. 7, n. 1, p. 57-74, jan./jun. 2011.

TREVES, Tullio. Coastal States' rights in the maritime areas under UNCLOS in Revista de Direito Internacional, v. 12, n.1, 2015. 
Para publicar na Revista de Direito Internacional, acesse o endereço eletrônico www.rdi.uniceub.br ou www.brazilianjournal.org.

Observe as normas de publicação, para facilitar e agilizar o trabalho de edição. 